\title{
Understanding Mechanisms of Resilience Economy- Live Application on a Complex Business Model
}

\author{
Mohamed Buheji \\ Founder \\ International Institute of Inspiration Economy, Morocco.
}

\begin{abstract}
"Resilience" as a concept has been re-discovered by many researchers from different disciplines in the last few years as it answers the demands for sustainable dynamical systems and way thinking that need to be addressed to rehabilitate different problems in our world today. This paper reviews the concept of resilience in order to develop from it a proposed mechanism for tackling problems and techniques that would lead to inspiration of the business model of any organization or society. An application of the proposed mechanism is implemented on the Water Supply Service loss and leakages as a challenging problem that is faced usually by most of the water utility and authority companies all over the world, but with varying magnitude, is reviewed. Being a complex business model, going through different challenges in many developed and developing countries, resilience mechanism is applied to identify how to improve the capacity of the system and make it more resilient without increasing its expenditure or affecting it supply stability. The study goes to see how the mechanism of resilience economy, adopted from the literature reviewed, could help to contribute to our understanding of the evolution of such system mechanism if we really to adopt a resilient mindset.
\end{abstract}

Keyword: Resilience, Resilience Economy, Coexistence, Intolerance, Inspiration Economy

\section{INTRODUCTION}

The concept of 'resilience' was first adopted within systems ecology in the 1970s, where it ignited the research of the cybernetics along with the complex systems theory.

Resilience today became an operational strategy and part of many risk and development management programs.

Resilience Economy (RE) is a new concept and field that is still in its early exploration and it focus on balancing the welfare impact whether in time of piece and disaster. Therefore, RE does not only depend on the physical characteristics of the event or its direct impacts in terms of lost lives and assets. (Duval and Vogel, 2008; Rose, 2004).

Resilience economy mechanisms targets to establish welfare impacts in the business model which depend on the ability of the economy to cope, recover, and reconstruct and therefore to minimize consumption losses. This ability that RE build in the business models can be referred to as the microeconomic resilience. (Duval and Vogel, 2008).

In this study we would try to understand from the literature review the influence that the mechanisms of resilience economy can bring in the different business models and specially in complex one and then we explore how this have been used during inspiration labs that brought major improvement to the reservation and conservation of a country essential natural resources, that water. (Fernandez, 2006). 
The paper discusses the economic resilience from different relevant points as culture and environment and what learnings can be taken relevant to 'stability'. Particular resilience practices are focused on as resilience in decision making, material diversity, investigations resilience, social integration and resilience towards sustainability in natural resources which is the focus of the context of study.

\section{LITERATURE REVIEW}

Definition of Resilience

"Resilience" is about the ability to absorb shocks while continuing to function. It's a word that has gained a lot of currency in recent years as more and more people realize that we have some big shocks headed our way: financial shocks, energy shocks, environmental shocks, as we as social unrest and international conflict. Rose (2004).

So resilience focus on the mental and then physical ability to recover quickly from depression, illness or misfortune. The physical property of material that can resume its shape after being stretched or deformed; elasticity. The positive ability of a system or company to adapt itself to the consequences of a catastrophic failure caused by power outage, a fire, a bomb or similar (particularly IT systems, archives). While the word resilient means able to endure, be bendable, be flexible, be strong without cracking, or with high ability to manage the impact of tribulation.

Resilience means we would be more ready to act as humans where mistakes are prone however, management of mistakes is what we should be ready for.

\section{Resilience \& Persistence}

Resilience needs persistence which is a continuance course of action in spite of difficulty or opposition. As with persistence we build the ability to recover from misfortune or change.

Perrings, C. (1998) Collaborative work between ecologists and economists has used the ecological concept of resilience to explore the relative persistence of different states of nature. The concept of resilience has two main variants. One is concerned with the time taken for a disturbed system to return to some initial state and is due to Pimm (1984). A second is concerned with the magnitude of disturbance that can be absorbed before a system flips from one state to another and is due to Holling (1986).

\section{Understanding Resilience from Nature}

The ecological concept of resilience focus on change in economy-environment systems. The linkages between resilience and the stability of dynamical systems as biodiversity and the sustainability of alternative states. Walker and Cooper (2011).

Recent developments in modelling the resilience of joint economy-environment systems suggest the advantages of analysing change in the system as a Markov process, the transition probabilities between states offering a natural measure of the resilience of the system in such states. It is argued that this 'emergent property' of the collaboration between ecology and economics has far-reaching implications for the way we think about, model and manage the environmental sustainability of economic development. (Duval and Vogel, 2008).

\section{Resilience \& Adaptation}

Resilience reflects a general consensus about the necessity of adaptation through endogenous crisis (Wong-Parodi et. al, 2015). The generalization of complex systems theory as a 
methodology of power has ambivalent sources. While the redefinition of the concept can be directly traced to the work of the ecologist Crawford S. Holling (1986), the deployment of complex systems theory is perfectly in accord with the later philosophy of the Austrian neoliberal Friedrich Hayek.

Since resilience deals with aspects of stability and adaptation it offers then system equilibria, thus offering alternative measures in relevance to enhancing the capacity of a system to retain productivity following disturbance. This support the inspiration economy main requirement, i.e. the ability to shift towards capacity vs. demand. Levin et al. (1998). Therefore, resilience became an enabler for managing the diversity in the Work Place and in managing the endogenous integration within the society.

\section{Resilience in Business Models}

Birchall (2009) focused about the importance of resilience designs in the business models to minimise economic crisis and improve the positive impact; using cooperative enterprises as a reference. Birchall showed how the consumer, worker and financial cooperative models all remained financially sound; reporting an increased turnover and growth despite the high economic instability. (Nsouli, 1995).

Birchall showed how the cooperative model of enterprise not only survives crisis, but also able to withstand crisis, maintaining the livelihoods of the communities in which they operate.

Therefore, establishing a resilience in business models can contribute to the organisations inspiration and effectiveness since it raises its ability to undermined changes in the internal and external environment in a very efficient way as mentioned by Sosna et. al. (2010).

Sosna and his team showed that resilience mechanisms built in business models of Spanish dietary products that was threatened by economic recession and heightened competition lead to help the business flourish and survive more and more. Resilience in the model of the dietary organisation made it outperform its competitors by a wide margin.

Resilience in business model means that we build a model that would meet high challenges and different life problems. It is a model that needs positive behavior in meeting challenges which leads to increasing the capacity to demands. The role of the model is also be a source of inspiration and directly or indirectly improve the overall socio-economic development. The model should help to ignited sustained feeling inspiration where is can be a point of reference for resilience economy, as shown in Figure (1). 


\section{Figure (1) Components of a Resilience Economy Business Model}

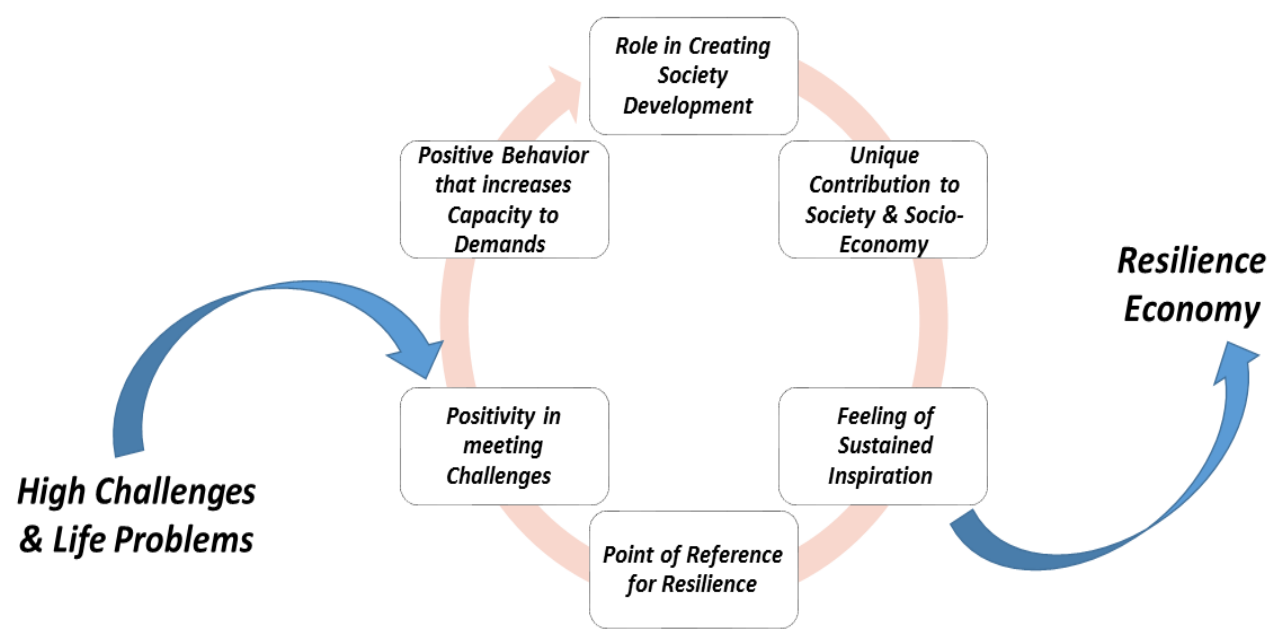

\section{Demand for Resilience Mechanisms in Our Societies}

Resilience mechanisms is rarely discussed in literature, even though it is highly demanded for all types of sectors and business in our societies and communities. Whatever the social status, the level of civilization and type of social fabric, resilience mechanisms can play a great role in creating better outcome with minimal resources.

Resilience in the designs of business models is highly needed today for the mindset of the middle class and decision makers in our societies, or those individuals responsible for the community services and development.

There many factors that influence the identification the type of resilience needed in business model, one of these factor is the problem that trigger the need for establishing a resilient mechanism. Therefore, we need to determine the particular behaviour of resilience that can be used to deal with the social problem.

\section{Introduction Resilience Economy}

Resilience economy is spreading more and more in different disciplines research such as in politics, economics, technology, finance, urban and environmental issues, security, social problems, psychology, problem solving, legal issues and policy management. (Kumpfer, 1999)

Resilience Economy requires identifying the scope of the business model in relevance to it socio-economic role, through recognizing or analyzing the model problem or challenges.

Resilience economy is much related to inspiration economy as mentioned in the work of Buheji (2016). Resilience economy requires restoration and adaptation while inspiration economy focus on adoption and innovative development with minimal resource. Please refer to Figure (2) 
Figure (2) Relation of Resilience Economy and Inspiration Economy.

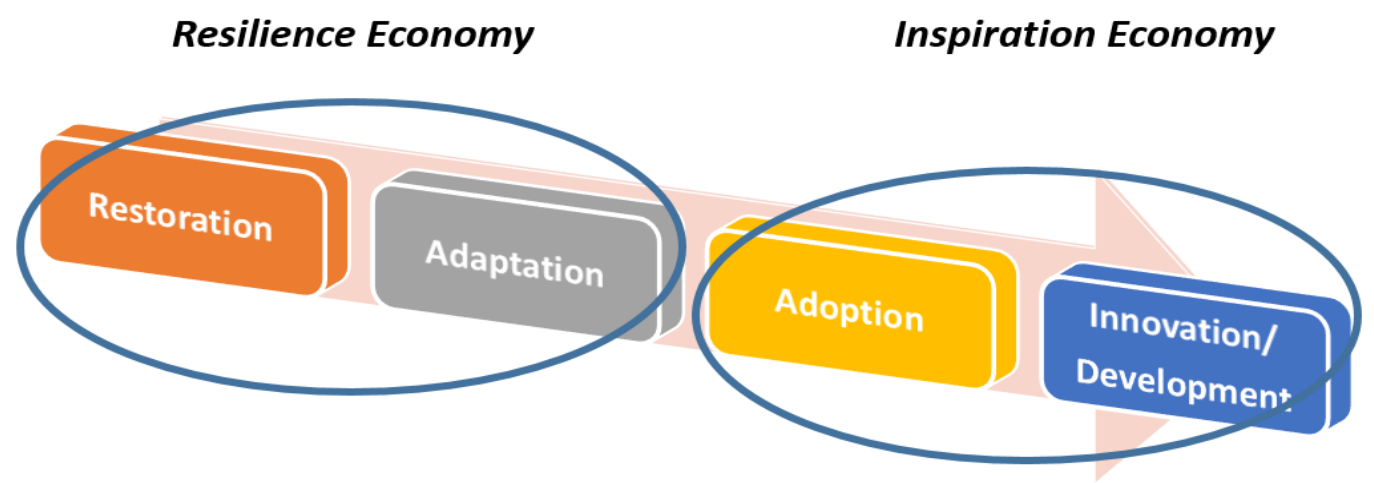

Resilience economy focus on managing the deviations in the socio-economic mechanisms. NonResilience is considered a weakness in considered a weakness in the business model and it is an abnormal state because it does not reflect the social aspect of humanity.

Resilience Economy focus on the studying the business model that lead to the current living conditions of poor immigrants. For example, we need more resilience practices from Europeans, whom accepting African and Asian migrants every day in their countries and where those migrant are settling in urban cities that are known for their social mobility. We need resilience practices in dealing with people from the underdeveloped areas of the Slums, where deep poverty, crime, delinquency, rift families and ethnic strife are preventing youth from seeing their dreams possible or achievable.

Same applies in the issue of dealing with the business model that guarantee the sustainability of essential water and energy supply. The business model need to be resilient enough to minimize energy or water loss, while maintaining continuity of services.

Resilience economy therefore aims to study the deviant behaviour and identify the social problem and then find means to solutions that would help develop the socio-economic status.

\section{Business Model Resilience \& Deviant Behaviour}

When individuals realize the existence of a business model problem they are working on, they take different and varied positions towards this. The positions of each individual differ according to the degree of proximity or distance from the problem. Their ability shift to focus on distancing themselves from the problem; instead of deeply understanding the opportunities of resilience in the model itself. (World Bank, 2013).

Since resilience is about mitigation and management of feelings or practices that leads to the indifference, people need to control their attitudes and practices in a way that would enhance the business model resilience.

In almost every type of specialty when the industrialization and urbanization increases the socio-economic problems increases in a very disorganized and deviant way that affects the human behaviour and the way the business model is delivered. This applies even to water utility services which is the context of this paper. 
The resilience mechanism help to build socio-economic disintegration in the business model between the concerned parties, thus establishing Total People Involvement that would undergo with the value system in the community targeted.

Resilience is considered a compact against any socio-economic disintegration that lead to more dependence on specific resources in the business model. Resilient models does not mean conforming to the standards and values of the community, but it is about ability to adapt. For example building resilience economy model in order to manage the issue of migration from south to north would need more resilience in education of immigrants to solve their problems by creating for them mindsets that would build self-fulfilment supported by mentorship and educational programs.

The concept of perverse behaviour refers to deviation from causes of consistent behaviour. The behaviour of an incompatible business model usually creates a challenge to the legitimacy of social norms. Through resilience we can overcome the uncoordinated business processes efforts which leads to behaviourally deviant practices.

Resilient models prevent the interference between socio-economic problems, deviation and disintegration. With resilient models all sources of frustrations would be dealt with as early as possible to avoid reaching disintegration breaks out.

\section{From Unstable Socio-Economy Practices to Resilience Economy Mechanisms}

Today more than ever before we need resilience mechanism to make our communities readier to be challenged as opposed to what might learned from interaction and from challenging current state of our lives.

Resilience economy mechanisms focuses on the classification of the business model problems that an organisation or a community faces towards pattern of stability adaptation.

In order to shift from unstable socio-economy to a resilient economy we need first to deal with the set of recurrent problems resulting from adapting to the external environment. To direct the outcome of the set of problems to satisfy the different business model component needs.

In order also to shift from unstable socio-economy we need to build mechanisms that turn the negative affect of the problems to positive one. This would eliminate gradually the negative behaviour that demands confrontation and increase the probabilities for achieving the model stability, as illustrated in Figure (3). 


\section{Figure (3) Shifting from Unstable to Resilience Economy}

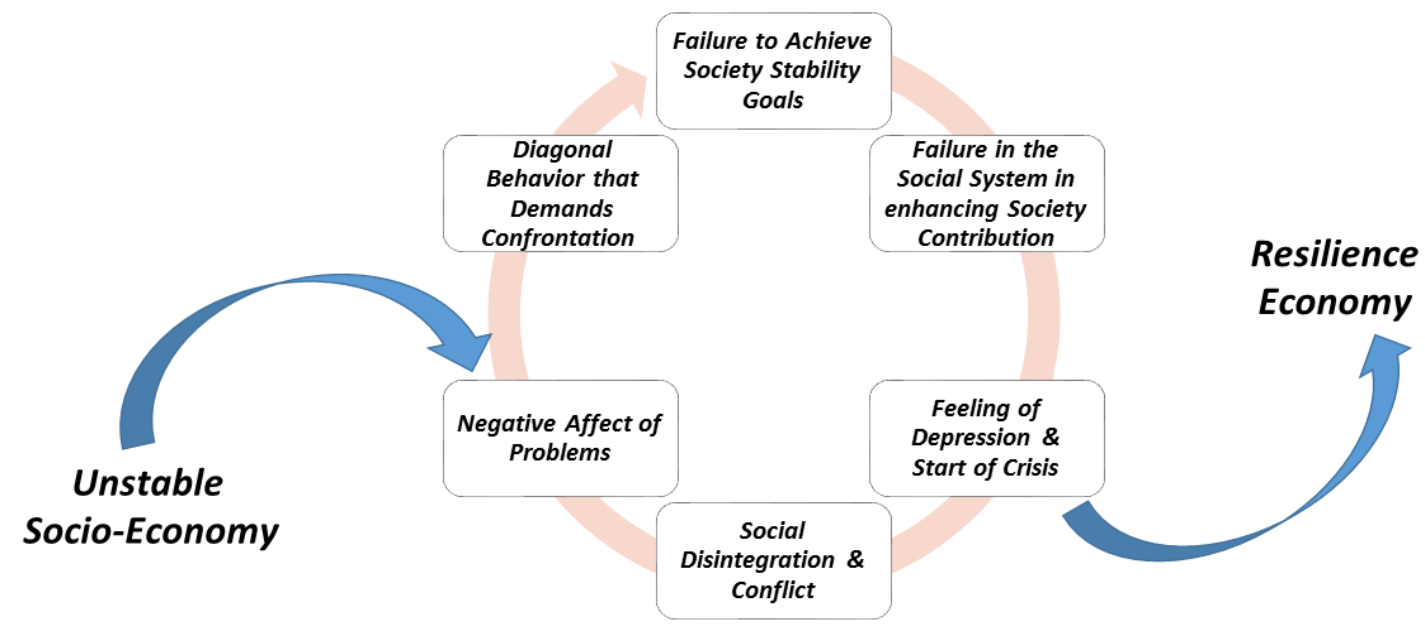

In order to build resilience in the business model people need to be more aware of the problem, the clearer the problem becomes the more we can create a transformation from unstable socio-economy to a resilience economy. The resilience mechanisms should help overcome problems and overcome the possibility of any mental rejection.

Therefore business models problems can be classified into fundamental business model problems linked to the lack of basic failure to deliver services or products relevant to the core of the business model, or non-satisfactory business model problems, or synergetic business model problem that is linked to the bad relations between different stakeholders of business model or the problem.

\section{Role of Resilience Economy in Managing Complex Models}

The resilience practices help to mitigate the level of problems in the business model. Hence with resilience mechanisms we mitigate the strong impact of problems on the surrounding socio-economic conditions, or minimize the adverse conditions and results that are mainly caused by socio-economic problem affects, or reduce the harmful conditions which are directly or indirectly the product of the socio-economic problems on the business model.

Resilience economy mechanisms help to manage the challenges caused by the vulnerability of problem failures and raise the targeted business model adaptive capacity, as Figure (4) shows. The larger the population density that the business model applies for, the more complex the problem becomes and the more diverse its causes and sources, and the more its forms and types. Röhn et. al. (2015). 
Figure (4) Role of Resilience in Managing Challenges

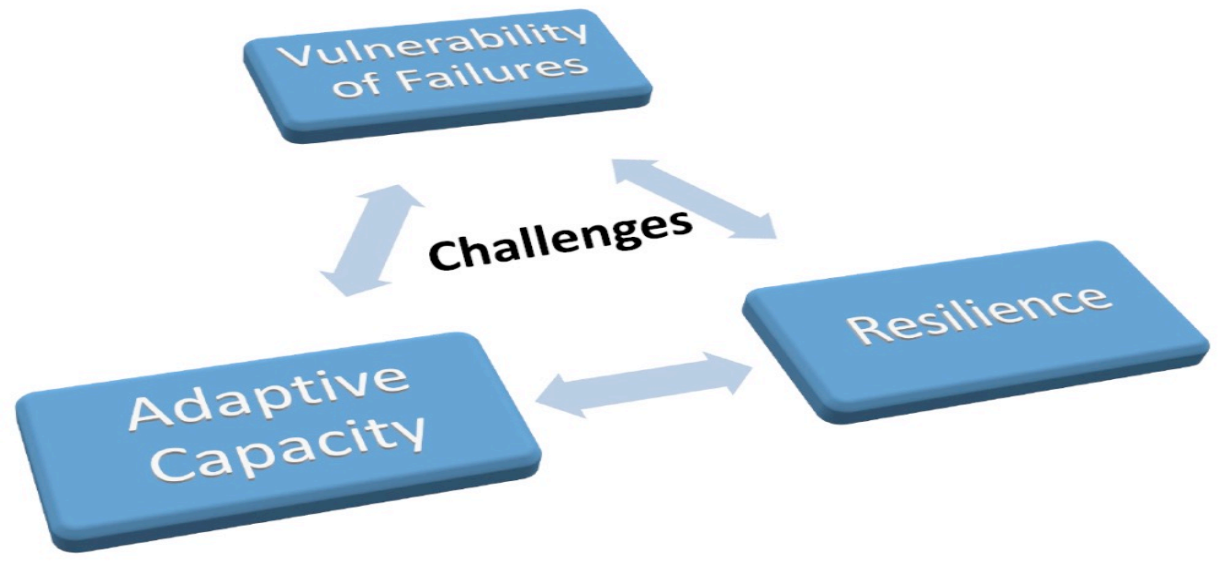

With the spirit persistence and the mechanisms of resilience, the creation of successful business models even in complex environment is highly possible as this leads to greater insight that, in turn, leads to new waves of seeing hidden opportunities (Buheji, 2016). Once this resilience is established in the targeted culture, the inspiration starts to enhance our abilities to see solutions inside each difficulty, thus helping us to focus on sustained resilient models outcomes.

Creating inspired resilience economy business models need to maintain diversity of solutions with high levels of communication. This establish resilient business models that can apply formula for sustenance of change. As we go through complex business model, we need to go through four stages, as shown in Figure (5). The first stage concerns going through a shift in cultural focus from 'what is wrong' to 'what works' in the business model. This means we need to be more resilient in terms of observing and discovering. Once we can absorb opportunities of resilience better outcomes can be generated.

Figure (5) Journey of Resilience in the Inspiration Labs

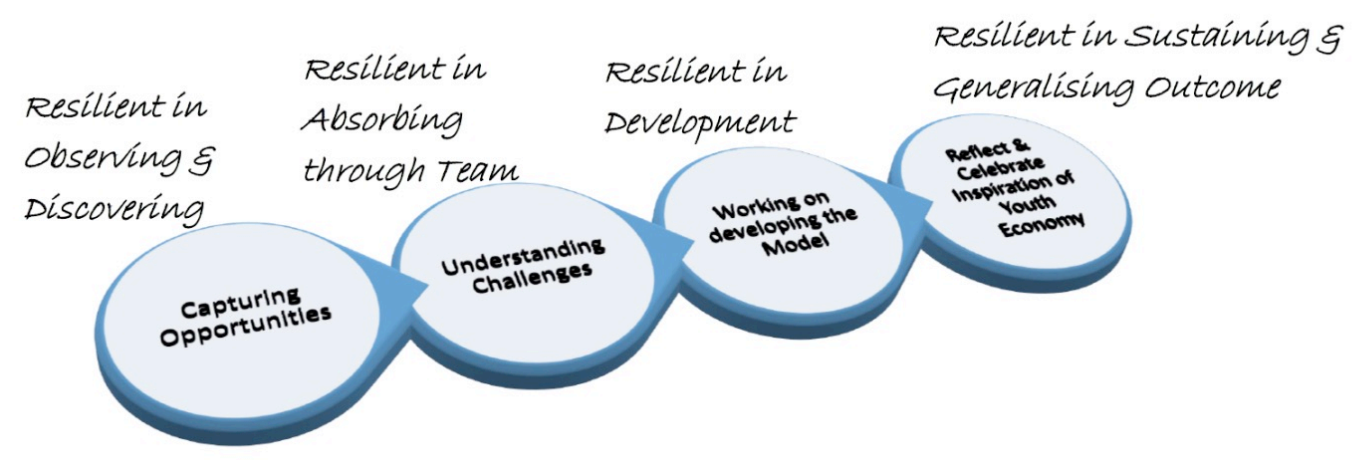

\section{Development of Resilience Economy Mindset through Inspiration Engineering}

Studies show that the business model is healthy (with high communication) and is profitable (with high value added) practices. The more Healthy and Profitable the business model is the more its mechanisms would be resilient. stability that will lead to acceptance; this establishes the first cycle in learning resilience. As we move towards greater sustainability, we will feel the importance of abundance thinking.

Resilient mindsets will develop individuals and communities that are cooperative and selfsufficient, self-initiated and proactive (Birchall, 2009). Moreover, resilient mindsets lead to 
more positive thinking, making more likely to be risk takers with a high ability to manage uncertainties. This is shown in Figure (6).

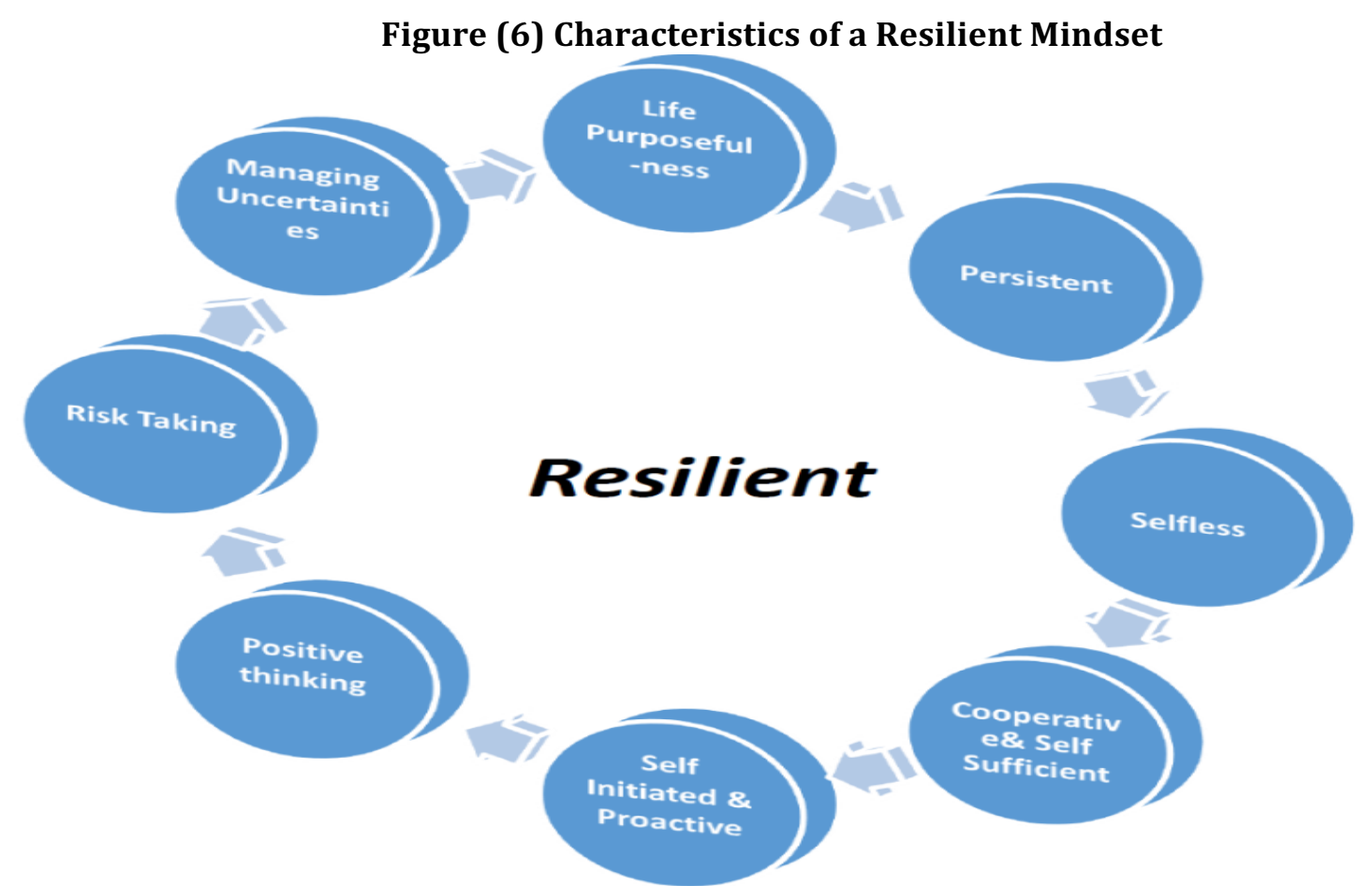

Therefore, it could be said that resilience mechanism create inspirational edge in the business model. Once the resilience of the model is started change agents are needed. Through the spirit of resilience, we can establish research and development clusters within the organisation.

We can deliver more focused goodwill working practices that are reflected in socio-economic business model outcome.

At we start the process of observations and exploring opportunities in the business model, the capacity for resilience automatically raised. Our ability to absorb what we learned during the exploration stages will increase our ability to find more opportunities thus enhancing our knowledge and inspiration sources. (Buheji, 2006).

As we synthesise and absorb the results of observation, we start to shift towards a new realisation of 'what we can do' to change and develop our mindsets about the business model, as illustrated in Figure (7). 
Figure (7) Capacity for Business Model Resilience during after the Inspiration Lab and its Role in Changing Mindsets

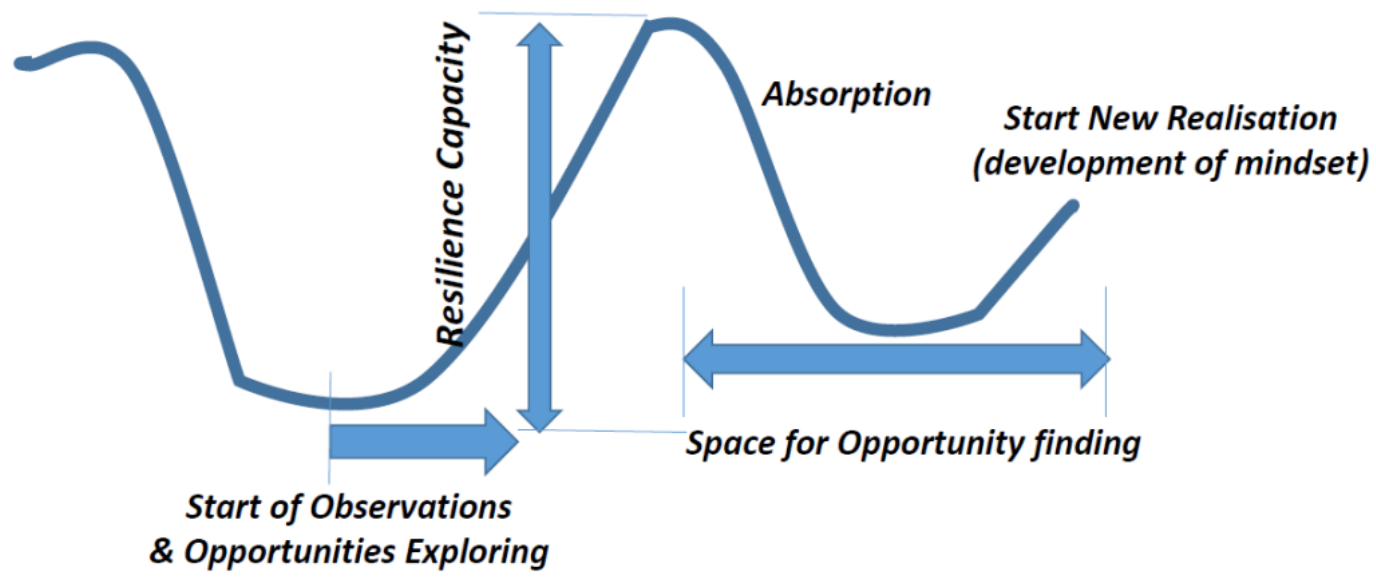

Reivich and Shatte (2003), authors of 'Resilience Factor', found that overcoming life's hurdles requires us to break down a problem into parts and determine which one can be solved first; we then fix what we can and then let the rest go. Resilience in Inspiration Labs is developed gradually based on this practice. Through practising more and more the capturing of opportunities, understanding the challenges, and working on the development of a model, we can clearly reflect and learn from the inspiration journey.

With the presence of resilience absorption techniques the amplification of the problem is in control, thus we avoid reaching a situation where the general public works on their discontent and discomfort. With resilience economy we can mitigate the possibility of amplification of the problem and minimize its size and effects in a way that it can be easily handled by the reformers.

\section{METHODOLOGY}

The research methodology employed in this paper is a qualitative case study. The case study was chosen as a method because it is suitable for situations that include complex and multiple variables and processes (Yin, 2003). A longitudinal case study that was carried over a period of 6 months examined the complex business model of the water production management in the kingdom of Bahrain. With this kind of qualitative method it was important to capture the resilience mechanisms used during the inspiration lab that lead to creating a resilience economy compliant business model in relevant to water production with minimal water loss.

The case study enabled an investigation into real-life events about specific evidence of resilience practices that started with interviews and observations. The paper attempts to address the research question: "How can Resilience Economy Mechanisms work to inspire complex Business Models?', i.e. ensuring the transformation of the model to be more robust and agile.

As is typical in case studies (Meredith, 1998), the case data were collected from multiple sources: thematic discussions, workshops and interviews with water authority representatives, besides concerned stakeholders. Following the principles of action research, the researcher and the actors in the case wanted to solve the urgent immediate problem of business model and this reflected on the development of process of problem-solving and great experiential learning teamwork. 
The interviews and trial and error field testing under what is called inspiration labs helped to get the water authority decision makers and key stakeholders more attached to the development of better business model that handle water loss in a country that is surrounded by sea and with no sweat water except from the little remaining wells.

The business model of water production and supply directorate was based on the supply of pure water from main stations to every consumer in the most efficient way, i.e. with minimal loss. Through Inspiration Engineering and Labs and unique approaches in problem solving resilient business model was pushed with the purpose to minimise the water loss even with the fast expansion of the water network system, due to boom in population.

In this case, the socio-economic issue was minimising loss of the $40 \%$ leakage in the utility water supply network by inspiring the water authority as an organisation, and enhancing its teams ability to discover early underground leakages and losses through observation and forecasting, and then by applying a level of intelligent decision making. The techniques went through the following main steps in order to gradually enhance the mechanisms of economic resilience in the water authority business model:

\section{Step (1) Understanding the Problem be Solved}

We can't start any problem solving without understanding what is the essence of the problem, i.e. realising the amount of water loss in the country because of system leakage between the source (the main water desalination stations) and delivery points (customers' water input points); despite the increase in the maintenance budget for water pipes and the overall water network.

\section{Step (2): Realising the impact of the problem on natural resources in the future.}

We started here by understanding the taxonomy of 'water loss' and its differentiation from 'water leakage', then applying this differentiation to check the difference.

\section{Step (3): Outline the Scientific Method for Problem Solving}

In order to outline the problem we needed to start setting proper resilience analysis of the business model and how the water authority handles the water leakage incidents and accidents by asking the participating teams to:

a) Codify the type of water loss and leakage.

b) Classify the categories of water loss and leakage in terms of place, time, type of area, pipe designs and detection equipment.

c) Specifying the relation and the correlation between seen (visible) and hidden (invisible) water loss (both from an analysis of previous history and field observations).

\section{Step (4): Studying Attitudes in terms of Inspiration Economy Requirements}

Without understanding the attitudes towards the business model problem can't be solved, thus in this stage we need to start:

- Identify the types of emergency readiness relevant to stopping water loss (both the seen and the hidden).

- Identify the average length of time taken to rectify a loss of water by type and area, besides the type of field response team needed.

- Understand all the challenges in compacting water loss and leakage as regards the type and amount of consumer areas, the age of the water network, the level of consumption, the type of real estate (i.e. normal domestic consumer, public consumer or private company, etc.). 
Step (5): Start Reasoning with regard to the Problem to ease the Complexity of the Water Supply Business Model (by Applying Suitable Convergent and Divergent Thinking Approaches).

Using both convergent and divergent thinking is very important for creating an opportunity from a challenge or a problem. In order to achieve this we need to:

- Start reasoning the type and amount of water leakage by the level of building heights and the size of population.

- Use reasoning to re-engineer the process of water loss and water leakage, and the way this impact the response team readiness. This should help to identify and then remove the non-value-added steps.

- Train, drill and deploy teams to effectively isolate the area network from the main water supply network.

- Enhance water loss detection equipment in areas that are prone to experience hidden water loss due to their history, type of design, and forecast data.

- Start piloting projects in three main areas/types of water consumer: old areas, new areas, large consumers.

\section{Part (6): Start Re-phrasing the Problem}

In order to solve a complex problem we need to re-phrase it, by:

- Categorise the type of challenges in each area and segregate the issues of illegal connections that count for part of the water loss problem.

- Design specific water pipes for tight areas which would be unique in size and thickness; these include characteristics to make them flexible yet robust.

\section{Part (6): Reducing the Problem's Complexity}

- Both the business model and the problem complexity were reduced throughout the inspiration lab journey in order to create more resilient economy model through:

- Understanding the types of defect in water meters that lead to slow detection and hence slow response of the emergency team.

- Understanding the places where leakage occurs inside houses and study trends or repetitions in terms of the types of connection.

- Building a 'Water Loss Intelligence Programme' that will enhance (i.e. inspire) the Water Authority to respond proactively to potential water loss on time and with high availability, better efficiency, and more effectively.

- Applying a 'Mitigation of Risks Programme' to support the 'Water Loss Intelligence Programme'.

This project helped to reduce the business model complexity and make more resilient and also reduced the country water loss by $30 \%$. The details of the numbers of all the above were removed to maintain confidentiality.

\section{DISCUSSION \& CONCLUSION}

Working on applying Resilience Economy mechanisms on national critical issues as major water loss could be a very strong technique to handle complex business models of different nature. With resilience mechanisms focused on the business models development and problem solving we can improve the welfare impacts on many types of socio-economic issues. With micro-economic resilience, we can manage the distribution of losses or mitigate causes of vulnerability. When our systems are economically resilient we would be more ready mitigate risks and absorb shocks. 
In resilient economy improved business models can influence positively more the socioeconomy and enahce the learning outcome. The learnings from the water authority loss and leakage case study is that business models can far more resilient if we focus on its socioeconomic system and work on to compensate its immediate losses, however complex it is. Therefore, it is advised that more research work is done to freely generalise the importance of resilient economy mechanisms and its ability to minimize welfare losses for any type of business model regardless of its given magnitude.

\section{Reference}

Birchall, J (2009) Resilience of the Cooperative Business Model in Times of Crisis, International Labour Organisation

http://www.ilo.org/empent/Publications/WCMS_108416/lang--en/index.htm

Buheji, M (2016) Handbook of Inspiration Economy. Bookboon. ISBN: 978-87-403-1318-5. http://bookboon.com/en/handbook-of-inspiration-economy-ebook

Duval, R. and L. Vogel, (2008) Economic resilience to shocks. The role of structural policies, OECD

Fernandez, R (2016) 5 Ways to Boost Your Resilience at Work, Harvard Business Review, June.

Hill, E; Wial, H and Wolman, H (2008) Exploring Regional Economic Resilience, Working Paper, Institute of Urban and Regional Development. https://www.econstor.eu/handle/10419/59420

Holling CS (1986) Resilience and stability of ecological systems. Annual Review of Ecology and Systematics 4: 123.

Holling CS (1986) Resilience of ecosystems: Local surprise and global change. In: Clark WC, Munn RE (eds) Sustainable Development of the Biosphere: Cambridge: Cambridge University Press, 292-317.

Kumpfer, K (1999) The Resilience Framework, Factors and Processes Contributing to Resilience, Resilience and Development. Part of the series Longitudinal Research in the Social and Behavioral Sciences: An Interdisciplinary Series, pp 179-224.

Lange 0 (1949) The practice of economic planning and the optimum allocation of resources. Econometrica 17: $166-171$.

Nsouli SM, (eds) (1995) Resilience and growth through sustained adjustment: The Moroccan experience. International Monetary Fund Occasional Paper No. 117. Washington, DC: International Monetary Fund.

Perrings, C. (1998) Resilience in the Dynamics of Economy-Environment Systems, Environmental Resource Economical, Vol. 11 (3-4): pp. 503-520.

Reivich, K and Shattle, A (2003) The Resilience Factor: 7 Keys to Finding Your Inner Strength and Overcoming Life's Hurdles, Harmony; Reprint edition (October 14, 2003)

Röhn, O., A. Caldera Sánchez, M. Hermansen and M. Rasmussen, (2015) Economic resilience: A new set of vulnerability indicators for OECD countries, OECD Economics Department Working Papers, No. 1249, OECD Publishing, Paris.

Rose, A (2004) Defining and measuring economic resilience to disasters, Disaster Prevention and Management: An International Journal, Vol. 13 Issue: 4, pp.307-314, https://doi.org/10.1108/09653560410556528

Sondermann, D (2016) Towards more resilient economies: the role of well-functioning economic structures, Reports No. 1984 November, European Central Bank, Working Paper.

Sosna, M; Nelly, R; Rodriguez, T; Velamuri, S (2010) Business Model Innovation through Trial-and-Error Learning: The Naturhouse Case, Long Range Planning, Volume 43, Issues 2-3, April-June 2010, Pages 383-407

Walker, J and Cooper, M (2011) Genealogies of Resilience,

Washington, DC: World Bank.

Wong-Parodi, G; Fischhoff, B; Strauss, B (2015) Resilience vs. Adaptation: Framing and action, Climate Risk Management 10: 1-7.

World Bank (2013) World Development Report 2014: Risk and Opportunity—Managing Risk for Development, Yin, R. (2003) Case Study Research, Third Edition Sage 